\title{
Testosterone, cortisol and catecholamine responses to exercise stress and autonomic dysreflexia in elite quadriplegic athletes
}

\author{
G Wheeler PhD,${ }^{1} \mathrm{D}$ Cumming MB ChB,${ }^{2} \mathrm{R}$ Burnham MD,${ }^{1}$ I Maclean MSc,${ }^{3}$ \\ B D Sloley PhD,${ }^{4}$ Y Bhambhani $\mathrm{PhD},{ }^{5} \mathrm{R}$ D Steadward $\mathrm{PhD}^{1}$ \\ ${ }^{1}$ Rick Hansen Centre, W1-67 Van Vliet Centre, ${ }^{2}$ Department of Obstetrics and \\ Gynecology (Division of Endocrinology) 1-D1 Walter C Mackenzie Health Sciences \\ Centre, University of Alberta Hospital, ${ }^{3}$ Faculty of Physical Education and Recreation, \\ ${ }^{4}$ Department of Zoology, Faculty of Science, ${ }^{5}$ Department of Occupational Therapy, \\ Faculty of Rehabilitation Medicine, University of Alberta, Edmonton, Alberta T6G 2H9, \\ Canada.
}

\begin{abstract}
Episodes of short high intensity exercise are associated with an increase in circulating total testosterone $(\mathrm{T})$ in men. Mechanisms may include hemoconcentration, decreased metabolic clearance and/or increased synthesis. Beta-blockade abolishes the $\mathrm{T}$ response suggesting a direct beta-adrenergic effect on the testes. Some spinal cord injured (SCI) athletes deliberately induce autonomic dysreflexia (boosting) to enhance performance. Associated with this practice are elevated catecholamine (CA) levels and exaggerated responses to serum catecholamine levels. Since basal $\mathrm{T}$ levels are reported to be normal in the SCI male, the $\mathrm{T}$ response to acute high intensity exercise might be expected to be exaggerated by boosting and associated elevated CA levels. The acute exercise $\mathrm{T}$ response has not been examined in SCI men to date. To determine whether the increased $\mathrm{CA}$ values associated with boosting enhanced the exercise-induced $\mathrm{T}$ elevation we measured circulating levels of $T$, cortisol $(C)$, norepinephrine (NE) and epinephrine (E) before and after maximal exertion and a simulated $7.5 \mathrm{~km}$ race with and without boosting in eight elite quadriplegic athletes. Maximal incremental exercise and a simulated $7.5 \mathrm{~km}$ race resulted in a rise in $\mathrm{T}$ similar to able bodied men under normal exercise conditions. Under boosted conditions the rise in $\mathrm{T}$ was eliminated while $\mathrm{NE}$ levels were significantly elevated above unboosted levels. The data may suggest an inhibitory role for $\mathrm{CA}$ on $\mathrm{T}$ production or release under conditions of extreme stress. Other possible mechanisms include $\mathrm{C}$ induced suppression, impaired gonadotropin stimulation of the Leydig cell and CA mediated alterations in gonadal blood supply.
\end{abstract}

Keywords: spinal cord injury; autonomic dysreflexia; performance enhancement; testosterone; catecholamines.

\section{Introduction}

Increased testosterone $(\mathrm{T})$ levels under acute high intensity exercise conditions were first reported by Sutton et al. ${ }^{1}$ Since then many research groups have replicated these findings. ${ }^{2-4}$ In contrast to these findings, prolonged exercise bouts such as ultramarathons and marathon races are associated with a decline in total $\mathrm{T}$ levels with delayed return to baseline levels. ${ }^{5-9}$ Chronic endurance training has also been associated with a physiological reduction in total $\mathrm{T}$ and the biologically available portion in circulation. ${ }^{11,12}$ It is likely that this reflects the summative effects of repetitive endurance training with minimal rest in between exercise bouts. ${ }^{5}$ For a complete review of the area the reader is referred to the review articles by Cumming et $a l^{5}$ and Cumming \& Wheeler. ${ }^{10}$

Mechanisms of increased $\mathrm{T}$ with acute maximal exercise bouts may include hemoconcentration, ${ }^{13}$ decreased metabolic 
clearance $^{1}$ and/or increased production. ${ }^{4}$ The inconsistent and delayed luteinizing hormone $(\mathrm{LH})$ response to acute high intensity exercise and the prompt response of testosterone levels suggest that LH mediated mechanisms are not involved. ${ }^{10}$

The sympathetic nervous system can also influence testosterone production through direct neural pathways and perhaps circulating catecholamines. ${ }^{14,15}$ Short term strenuous activity produces a substantial increase in circulating catecholamines ${ }^{3,16}$ and betablockade abolishes the exercise associated serum testosterone increase. ${ }^{3,17}$ The response of the hypothalamic pituitarygonadal (HPG) axis to acute high intensity exercise has not been investigated in men with spinal cord injury (SCI) although baseline $\mathrm{T}$ levels in this group appear to be normal on stabilization following an initial trauma-induced suppression. ${ }^{18-25}$

Anecdotal reports have suggested that some quadriplegic athletes intentionally self-induce autonomic dysreflexia (AD) to enhance performance during competition. This practice will herafter be referred to as 'boosting'. By intentionally overdistending the bladder, applying tight leg straps or sitting on pronounced objects, quadriplegic athletes generate nociceptive stimuli sufficient to induce $\mathrm{AD}$. AD occurs in SCI with lesions above the T6 level and is characterized by a nociceptive induced reflex sympathetic discharge resulting in peripheral vasoconstriction, hypertension and piloerection distal to the lesion. Hypertension results in stimulation of vascular baroreceptors activating the parasympathetic nervous system. Parasympathetic nervous system mediated vasodilation takes place above the lesion level and is characterized by facial flushing, vascular headache, nasal stuffiness and bradycardia. Although we have previously determined the effectiveness of boosting in enhancing quadriplegic race performance, the potential health hazards and moral issues accompanying its practice were also evident and have been discussed elsewhere. ${ }^{26}$ The exact mechanism of action of boosting in athletic performance is not clear.

Although resting levels of catecholamines are generally low in quadriplegics, AD following bladder distension results in increases in circulating catecholamines, particularly norepinephrine. ${ }^{27}$ Since CA has been implicated in the acute-exercise induced elevations in $\mathrm{T}$ then one might expect an exaggerated $\mathrm{T}$ response in SCI athletes using boosting since $\mathrm{T}$ levels at rest are normal in this population. ${ }^{18-25}$ In addition AD is associated with elevated cortisol (C) levels ${ }^{27}$ which have been suggested as a direct inhibitor of testosterone production. ${ }^{28,29}$ The SCI athlete thus provides a model to examine the effects of CA and C on the exercise induced increment in testosterone levels. To date the $\mathrm{T}$ response in SCI to acute exercise has not been documented.

\section{Purpose of the investigation}

We investigated effects of spinal cord injury and boosting on the exercise-induced increment in total $\mathrm{T}$ levels and serum $\mathrm{C}$ in a group of elite quadriplegic athletes. Specifically we addressed the following issues: (1) the effects of boosting (autonomic dysreflexia) on $\mathrm{CA}, \mathrm{T}$ and $\mathrm{C}$ responses to acute maximal exercise and a simulated $7.5 \mathrm{~km}$ wheelchair race; and (2) the relationship of $\mathrm{CA}$ responses to the $\mathrm{T}$ and $\mathrm{C}$ response to an acute exercise stimulus.

\section{Subjects and methods}

\section{Subjects}

Eight male quadriplegics (C6-8: seven motor/sensory complete and one incomplete) volunteered for the investigation. All were elite quadriplegic road race athletes who used the boosting technique. Approval was obtained from an institutional ethics committee and all subjects gave informed consent following a detailed explanation of the purpose and procedures of the investigation. All subjects completed a questionnaire regarding boosting practices. ${ }^{26} \mathrm{~A}$ medical emergency triage protocol and hospital support system was established in accordance with that suggested by Braddom \& Rocco. ${ }^{30}$ Each subject provided a brief health history and underwent a preliminary medical examination conducted by the research team physician. All tests were conducted at the 
same time of day between 0900 and 1300 hours. Subjects selected a test time and maintained the schedule for the duration of the investigation.

\section{Methods}

Each subject underwent a series of six test procedures: two graded velocity maximal aerobic power $\left(\mathrm{VO}^{2} \max \right)$ tests and four simulated $7.5 \mathrm{~km}$ races. Tests were conducted under boosted and unboosted conditions. Simulated road races and maximal aerobic power tests were conducted with the athlete's own chair mounted on friction free rollers. Test order was randomized in order to minimize the effects of cumulative fatigue. Tests were conducted over a 9 day period with days 3 and 6 designated as rest days. The volume of exercise over the 9 day period was equivalent to each athlete's regular training routine. Subjects were transported to the laboratory to avoid fatigue, arriving at the testing area at least 30 minutes prior to testing and having avoided any strenuous activity for at least 12 hours. Subjects were instructed to arrive unboosted or in a self-induced boosted state according to the test schedule. On boosted test days, subjects were instructed to follow their normal race-day routines with regard to preparation, warm up and boosting. These conditions were matched on nonboosting days except for the boosting procedure itself. On arrival at the laboratory subjects were weighed on a specially adapted beam balance scale (Detecto-medic, Detecto Scales Inc, California). Resting blood pressure was taken by an automated system (Paramed model 9350, Paramed Technology Inc, California) and resting heart rate was taken via a PE sport tester (model 3000). Axillary body temperature was also measured (YSI model 47, Yellow Springs Instrument Co Inc, Ohio). After sitting quietly for 30 minutes, a $15 \mathrm{ml}$ resting blood sample was obtained from each subject by venepuncture. The sample was separated and treated for later analysis for CA (epinephrine (E) and norepinephrine (NE)), total T and C. All samples were kept on ice, and frozen at $-20^{\circ} \mathrm{C}$ for later analysis. Following collection of blood sam- ples, the subject was transferred to his racing chair already mounted on the friction-free roller system. Once wheel axle alignment was completed, each subject performed his routine warm-up procedure. Following warm up, subjects performed a $\mathrm{VO}^{2}$ max test or a simulated $7.5 \mathrm{~km}$ maximal effort race in either a boosted or. unboosted state.

\section{Maximal aerobic power test: procedure}

Subjects' chairs were mounted on the friction-free rollers. Subjects began wheeling at $10 \mathrm{~km} / \mathrm{h}$ and velocity was increased by $2 \mathrm{~km} / \mathrm{h}$ every 2 minutes until $\mathrm{VO}^{2}$ max was achieved. $\mathrm{VO}^{2} \max$ was defined as no further increase in oxygen consumption with two consecutive velocity increases ${ }^{31}$ or voluntary exhaustion. A $15 \mathrm{ml}$ blood sample was taken within 1 minute of completion of the test.

\section{$7.5 \mathrm{~km}$ simulated road race test}

The protocol was as per the maximal aerobic power test except that on command, the subject wheeled at maximum race speed for a distance of $7.5 \mathrm{~km}$. Verbal encouragement was minimized to ensure standardization of test procedures. Subjects were informed at $1,3.5$ and $7 \mathrm{~km}$ of distances travelled. Blood samples were collected within 1 minute of completion of the race. In order to obtain mid-race blood pressure measurements it was necessary to have the athletes stop wheeling for a 45 second period on an imaginary downhill section.

\section{Blood sample analysis}

Epinephrine (E) and norepinephrine (NE) were measured in plasma samples by HPLC in conjunction with a commercially available kit (Waters Plasma Catecholamine Kit, Waters, Millipore, Milford, Massachusetts). Total $\mathrm{T}$ and $\mathrm{C}$ were measured using commercially available RIA kits (ICN Biomedicals Inc, USA). All samples were measured in a single assay (coefficient of variation $<5 \%$ ). Specificity (cross reactivity) of the assays for total $\mathrm{T}$ and $\mathrm{C}$ were both $100 \%$ with less than $2 \%$ cross reactivity for other compounds for total $\mathrm{T}$ and less than $3 \%$ for other hormones for the C assay. 


\section{Statistical analysis}

A two way analysis of variance with repeated measures was computed; (test type: $\max$ or $7.5 \mathrm{~km}$ race) $\times$ (test condition: boosted or unboosted) $\times$ time (pre test, post test) to analyze pre and post NE, E, T and $\mathrm{C}$ responses. Since boosted and unboosted simulated race tests were completed twice, mean $\mathrm{T}, \mathrm{C}, \mathrm{E}$ and $\mathrm{NE}$ values were used in the analysis. Significance levels were set at 0.05 .

\section{Results}

All subjects freely acknowledged the use of the technique to enhance performance. Bladder overdistension was utilized by seven subjects. This was induced by excessive pre-race fluid consumption. One subject obstructed urinary flow by clamping an indwelling catheter. The other subjects experienced boosting in association with reflex bladder contractions and uninhibited urine flow. One subject induced nociceptive input by sitting in the confined seat of his racing wheelchair for up to 2 hours prior to race time. Five subjects reported that boosting was an unpredictable response while three felt they could induce it reliably and maintain the effect. Importantly, subjects reported that they felt that between $90 \%$ and $100 \%$ of quadriplegic wheelchair athletes used the technique. Further details regarding questionnaire responses are reported elsewhere. ${ }^{26}$

Boosting was found to significantly improve race time $(9.7 \%, p<0.05)$ but was also associated with significant and occasionally dangerous blood pressure elevations. ${ }^{26}$ The boosting response was evoked reliably at some points in the simulated race procedure by all the athletes. However, intensity and maintenance of the boosted state were less predictable. Boosting occurred in an episodic fashion during the race with varying intensity, particularly in the athletes who relied on large pre-race fluid intake and no bladder obstruction. Evidence of boosting comprised marked facial flushing and vasodilation above the lesion level with concomitant gooseflesh (vasoconstriction) below the level of the lesion.

\section{Testosterone and cortisol}

\section{Testosterone}

No significant difference was found between test type $\left(\mathrm{VO}^{2} \max\right.$ vs $\left.7.5 \mathrm{~km}\right)$. There was a significant effect for time $(p<0.01)$ and for test condition $\times$ time $(p<0.001)$. Post hoc comparisons revealed that mean $\mathrm{T}$ levels were elevated by $30 \%$ after the unboosted $\mathrm{VO}^{2}$ max test although the change was marginally insignificant $(p<0.054)$. There was no change under boosted $\mathrm{VO}^{2}$ max test conditions. There was a significant 33\% increase in total $\mathrm{T}$ following the simulated $7.5 \mathrm{~km}$ race under unboosted conditions $(13.9 \pm 1.4$ to $18.6 \pm 2.1 \mathrm{nmol} / \mathrm{l})$ whereas levels under boosted conditions were unchanged $(16.03 \pm 1.2$ vs $16.28 \pm 1.4 \mathrm{nmol} / \mathrm{l})$ $(p<0.05)$. There were no significant differences in resting $T$ levels under either boosted or unboosted conditions.

\section{Cortisol}

Main effects for test type $(p<0.01)$, time $(p<0.001)$ and test type $\times$ time $(p<0.01)$ were significant. Post hoc comparisons revealed that $C$ levels remained unchanged under both boosted and unboosted conditions before and after the incremental maximal exercise test. C levels increased significantly from baseline to post exercise levels with a simulated $7.5 \mathrm{~km}$ race under both boosted $(361.2 \pm 46$ to $500.4 \pm 41 \mathrm{nmol} / 1)$ and unboosted $(287.2 \pm 33$ to $556 \pm 49$ $\mathrm{nmol} / \mathrm{l})$ conditions $(p<0.001)$. This represented $28 \%$ for boosted and $51 \%$ for unboosted conditions (Fig 1).

\section{Catecholamines}

Epinephrine

Main effects for condition, type of exercise and time were not significant and $E$ levels were not different at baseline measurement nor were changed with either mode of exercise (incremental maximum test or simulated $7.5 \mathrm{~km}$ race) or exercise condition (boosted or unboosted).

\section{Norepinephrine}

NE levels did not change under either boosted or unboosted conditions from pre to post maximal incremental exercise. However, NE levels were $70 \%$ higher at the 

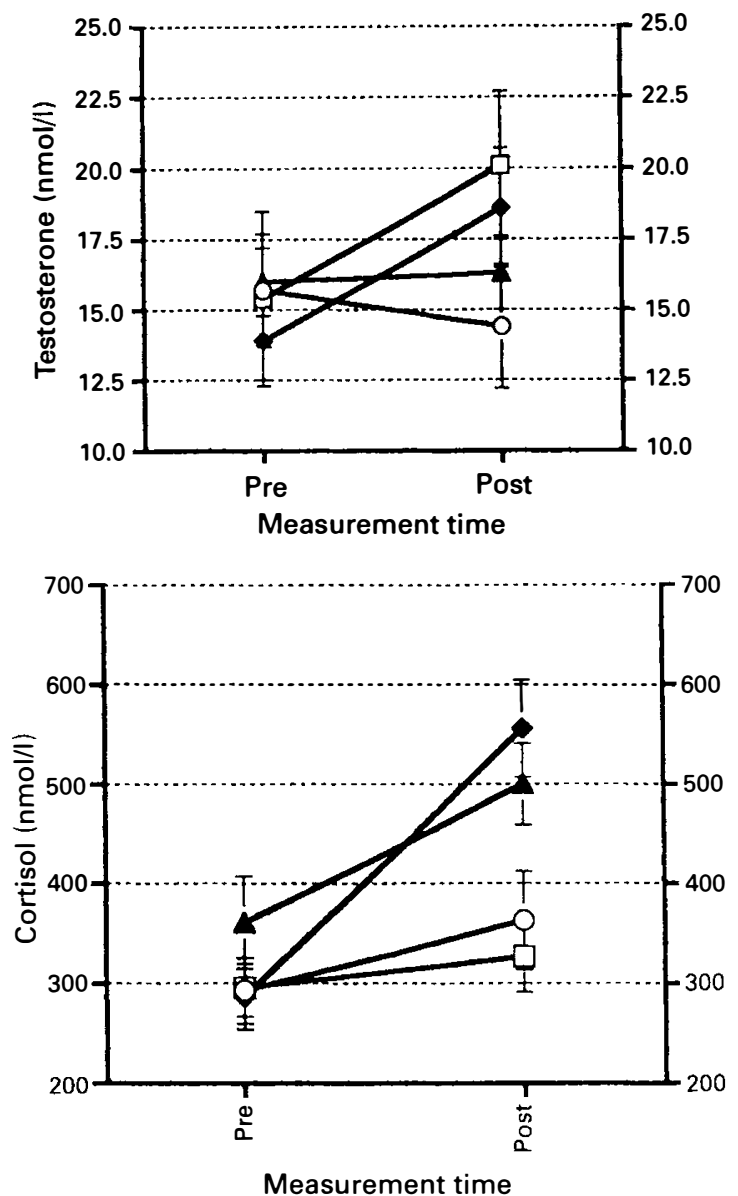

pre measure $(4.6 \pm 1.0$ v $2.7 \pm 0.6 \mathrm{nmol} / \mathrm{l})$ and $55 \%$ higher at the post measure $(4.5 \pm 0.7 \times 2.9 \pm 0.4 \mathrm{nmol} / \mathrm{l})$ for the incremental boosted maximal exercise test compared to the unboosted maximal exercise test. NE levels were significantly higher at rest $(5.1 \pm 1.1$ vs $2.3 \pm 0.2 \mathrm{nmol} / 1)$ and after exercise $(7.1 \pm 1.4$ vs $2.4 \pm 0.2 \mathrm{nmol} / \mathrm{l})$ under the boosted versus unboosted $7.5 \mathrm{~km}$ race condition $(p<0.01)$ and increased with exercise in the boosted condition $(5.1 \pm 1.1$ to $7.1 \pm 1.4 \mathrm{nmol} / \mathrm{l})(p<0.02)$. Resting levels were $220 \%$ greater in the boosted versus unboosted condition and almost $295 \%$ greater than the unboosted condition after the simulated $7.5 \mathrm{~km}$ race (Fig 2).

\section{Correlations}

Correlations among total T, C, E and NE

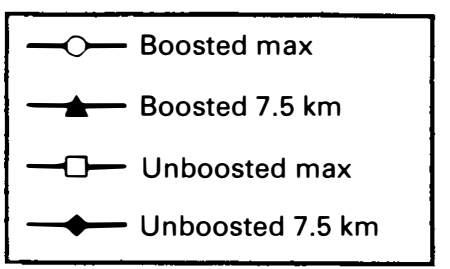

Figure 1 Total testosterone and cortisol values before and after boosted and unboosted $\mathrm{VO}^{2}$ $\max$ and $7.5 \mathrm{~km}$ test. Testosterone increased significantly following unboosted $7.5 \mathrm{~km}$ $(p<0.05)$ but not after unboosted $\mathrm{VO}^{2} \max$ $(p<0.054)$ cortisol increased following unboosted and boosted $7.5 \mathrm{~km}$ race $(p<0.001)$.

were modest and insignificant for boosted and unboosted test conditions and for incremental maximal exercise and the simulated $7.5 \mathrm{~km}$ race test.

\section{Discussion}

A difference in response was observed between maximal and $7.5 \mathrm{~km}$ test procedures. Hormone and catecholamine responses were typically associated with the $7.5 \mathrm{~km}$ and not the incremental $\mathrm{VO} 2$ max test. A clue to this may reside in the fact that our subjects were all wheeling at or close to maximum aerobic capacity $(92-101 \%$ VO2 $\max$ ) for the duration of the $7.5 \mathrm{~km}$ test but only reached near maximum or maximum levels for a brief period (less than 4 minutes) during the maximum test. The relative stress of this test was probably appreciably lower than the continuous race simulation. 

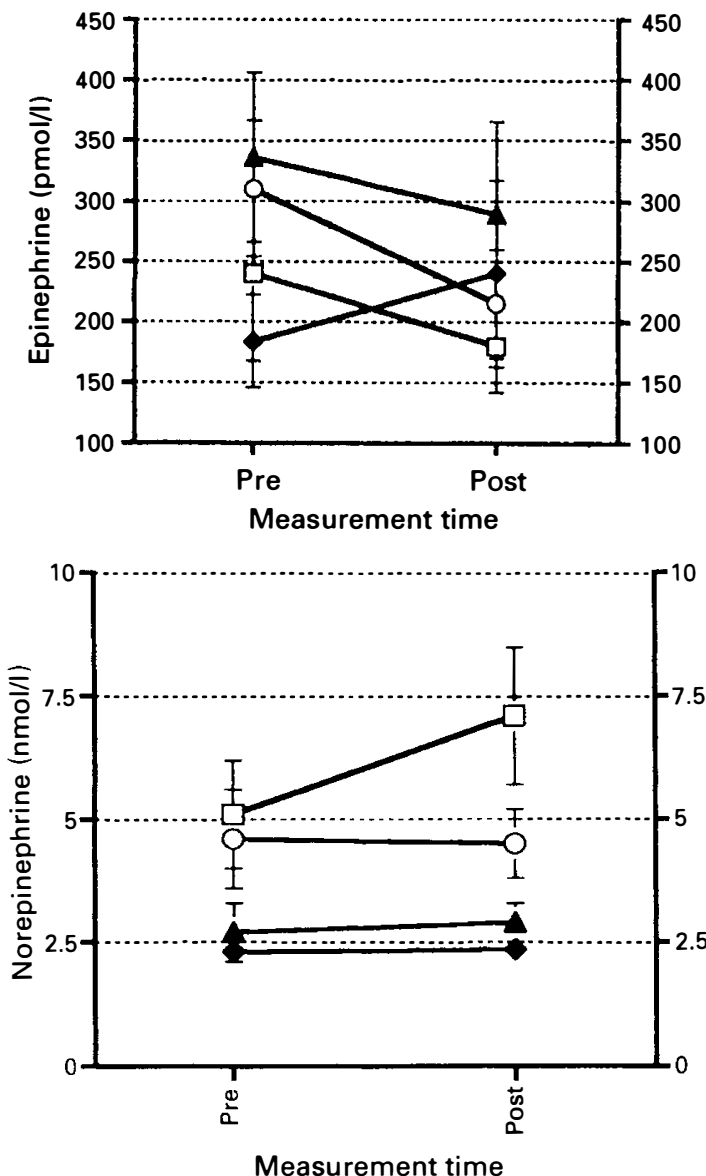

Circulating $\mathrm{T}$ levels are suppressed in men immediately following spinal cord injury but return to normal as the condition stabilizes. ${ }^{18-25}$ Serum $T$ levels in the elite athletes were at the lower end of the normal range and similar to values we have previously reported in high mileage runners ${ }^{11}$ and wrestlers in mid-season, ${ }^{12}$ suggesting that elite wheelchair athletes respond to training in a manner similar to able bodied subjects. Serum $\mathrm{T}$ levels in elite athletes also increased in response to short term strenuous unboosted exercise in a manner similar to able bodied individuals undergoing comparable activity. ${ }^{3,4}$ Basal serum $\mathrm{T}$ levels were not affected by boosting but the expected exercise-induced increase in serum $T$ was abolished by boosting. The absence of direct innervation of the testes suggests that humoral factors are involved in the $\mathrm{T}$ response and its abolition.

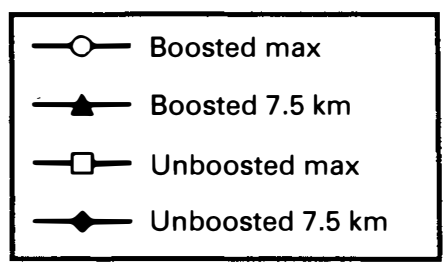

Figure 2 Epinephrine and norepinephrine values before and after boosted and unboosted VO2 max and $7.5 \mathrm{~km}$ test. Norepinephrine levels increased significantly following boosted $7.5 \mathrm{~km}$ race $(p<0.02)$.

Basal C levels were within the physiological range in both boosted and unboosted conditions although somewhat higher than previously reported in runners and able bodied controls. ${ }^{11}$ These high values probably reflected diurnal variation and higher morning values. They were, however, generally similar to afternoon values in wrestlers. ${ }^{12}$ The $\mathrm{C}$ response to activity did not differentiate between boosted and unboosted states suggesting that $\mathrm{C}$ was not a factor in the suppression of the testosterone increment in the boosted condition.

E levels were not significantly changed by either exercise or boosting while NE levels were substantially increased at baseline and after a $7.5 \mathrm{~km}$ race by boosting. Boosted and unboosted $\mathrm{E}$ and NE levels were lower than values previously reported in able bodied men but substantially higher than corresponding levels in basal and bladder 
distended spinal cord injured men. The apparent lack of an exercise-induced response may reflect insensitivity of the before and after protocol employed in the present study. Alternatively, this may also reflect a lack of adrenal medulla activity. The abolition of the $\mathrm{T}$ response to boosted exercise was a surprising finding since previous research indicates that beta-blockade abolished the exercise-associated $\mathrm{T}$ increment. ${ }^{3,17}$

A variety of mechanisms could be involved including adrenocortical stimulation, catecholaminergic mediated mechanisms and alterations in gonadotropin secretions and/or stimulation. A direct $\mathrm{C}$ mediated suppression of $\mathrm{T}$ production and/or the exercise-induced increment seems unlikely, since changes occurred without a cortisol response.

The role of elevated catecholamine levels must also be considered. Increased circulating levels of catecholamines during exercise have been associated with the acute exercise-induced elevation of total $\mathrm{T}^{1,16} \mathrm{Al}$ though a stimulatory effect of $\mathrm{CA}$ on $\mathrm{T}$ production has been suggested ${ }^{17}$ others have suggested an inhibitory role for $\mathrm{CA}$ on $\mathrm{T}$ production in $\mathrm{SCI}^{19}$ and $\mathrm{AB}$ men. ${ }^{15}$ This is consistent with suppressed $\mathrm{T}$ levels under various conditions of stress. ${ }^{32,33}$

Other, CA-mediated mechanisms may be considered and include down regulation of receptors at the Leydig cell level, alterations in testicular blood flow and CA effects on the HPG and HPA axis. Theories associated with receptor down regulation are consistent with a stimulatory effect of $\mathrm{CA}$ on $\mathrm{T}$ production. Low basal levels of circulating $\mathrm{CA}$ (such as found in SCI) produces an increase in receptor content (end organ hypersensitivity) whereas a sustained increase in $\mathrm{CA}$ levels produces a rapid decrease in receptor content in as little as 30 minutes. ${ }^{34}$ It is possible that sustained high or fluctuating levels of $\mathrm{CA}$ as a result of boosting resulted in a down regulation of testicular CA receptor activity or number, with a concomitant decrease in the $\mathrm{T}$ production rate.

E infusion decreases testicular blood supply ${ }^{35}$ and $\mathrm{T}$ levels in animals. ${ }^{15}$ Also, $\mathrm{T}$ production in animals is altered proportionally by rate of blood flow to the testes. ${ }^{36}$ Administration of $\mathrm{E}$ prevents $\mathrm{LH}$ secretion from the anterior pituitary ${ }^{37}$ and CA mediated vasoconstriction may further diminish LH supply to the testes. Since E levels were largely unchanged in our subjects and since no similar effects have been reported associated with NE increases, it is unclear whether a CA mediated alteration in blood flow was involved in the hormonal responses observed.

\section{Conclusions}

Our data suggests an inhibitory effect of CA on the exercise-associated $\mathrm{T}$ increment in contrast to previous reports. This may reflect alterations in testicular blood flow during autonomic dysreflexia or an unexplained direct CA mediated mechanism at the Leydig cell level.

\section{Acknowledgements}

This study was supported by Recreation Parks, Wildlife Foundation and Alberta Lotteries, Special Services and Research Committee, University of Alberta Hospital.

\section{References}

1 Sutton JR, Coleman MJ, Casey J, Lazarus L (1973) Androgen responses during physical exercise. BMJ 1: 520-522.

2 Mathur DN, Toriola AL, Dada OA (1986) Serum cortisol and testosterone levels in conditioned male distance runners and non-athletes after maximal exercise. J Sports Med Phys Fitness 26: 245-250.

3 Kindermann W, Schnable A, Schmitt WM, Biro G, Hippchen M (1982) Catecholamines, STH, Cortisol, Glucagon, Insulin und Sexualhormone bei Korperlicher Belasting und beta-blockade. Klin Wolrenschr 60: 505-512.

4 Cumming DC, Brunsting LA, Strich G, Ries AL, Rebar RW (1986) Reproductive hormone increases in response to acute exercise in men. Med Sci Sports Exerc 18: 369-373.

5 Cumming DC, Wheeler GD, McColl EM (1989) The effects of exercise on reproductive function in men. Sports Med 7: 1-17.

6 Tanaka H, Cleroux J, de Champlain J, Ducharme JR, Collu R (1986) Persistent effects of a marathon run on the pituitary-testicular axis. J Endocrinol Invest 9: 97-101. 
7 Schurmeyer T, Jung K, Nieschlag E (1984) The effects of an 110 kilometer run on testicular adrenal and thyroid hormones. Int J Androl 7: 276-282.

8 Morville R, Pesquies PC, Guezzenec CY, Serrurier BD, Guignard M (1979) Plasma variations in testicular and adrenal androgens during prolonged physical exercise in man. Annales d'Endocrinologie (Paris) 40: 501-510.

9 Dessypris K, Kuoppasalmi K, Adlercreutz H (1976) Plasma cortisol, testosterone, androstenedione and luteinizing hormone $(\mathrm{LH})$ in a non-competitive marathon run. J Steroid Biochem 7: 33-37.

10 Cumming DC, Wheeler GD (1990) Exercise-associated changes in reproduction: a problem common to men and women. Frisch RE, editor. Adipose tissue and reproduction. Progress in Reproductive Biology and Medicine. Karger, Basel, 14: 125-135.

11 Wheeler GD, Wall SR, Belcastro AN, Conger P, Cumming DC (1984) Reduced serum testosterone and prolactin levels in male distance runners. JAMA 214: 514-516.

12 Wheeler GD, Symbaluk D, Pierce WD, McFadyan S, Cumming DC (1992) Decreased testosterone and elevated serum cortisol in wrestlers. Clin Sports Med 2: 257-260.

13 Wilkerson JE, Horvath SM, Gutin B (1980) Plasma testosterone during treadmill exercise. J Appl Physiol 49: 249-253.

14 Eik-Ness KB (1964) On the relationship between testicular blood flow and secretion of testosterone in anesthetized dogs stimulated with human gonadotropin. Can J Physiol Pharmacol 42: 671-677.

15 Levin J, Lloyd CW, Lobotsky J, Friedrich EH (1967) The effect of epinephrine on testosterone production. Acta Endocrinol 55: 184-192.

16 Galbo H, Hummer L, Petersen LB, Christensen NJ, Bie N (1977) Thyroid and testicular responses to graded and prolonged exercise in man. Eur J Appl Physiol 36: 101-106.

17 Jezova D, Vigas M (1981) Testosterone response to exercise during blockade and stimulation of adrenergic receptors in man. Horm Res 15: 141-147.

18 Hirsh IH, Sedor J, Callahan HJ, Staas WE (1990) Systemic sperm autoimmunity in spinal cord injured men. Arch Androl 25: 69-73.

19 Ver Voort SM (1987) Infertility in spinal cord-injured male. Urology 24: 157-165.

20 Naftchi NE, Viau AT, Heiner-Sell G, Lowman EW (1980) Pituitary-testicular axis dysfunction in spinal cord injury. Arch Phys Med Rehabil 61: 402-405.

21 Claus-Walker J, Scurry M, Carter CE, Campos RJ (1977) Steady state hormonal secretion in traumatic quadriplegia. J Clin Endocrinol Metab 44: 530-535.

22 Mizutani S, Sonoda T, Matsumoto K, Iwasa K (1972) Plasma testosterone concentration in paraplegic men. $J$ Endocrinol 54: 363-364.

23 Hayes PJ, Krishnan KR, Diver MJ, Hipkin LJ, Davis JC (1979) Testicular endocrine function in paraplegic men. Clin Endocrinol 11: 549-552.

24 Morley JE, Distiller LA, Lissoos I, Lipschizt R, Kay G, Searle DL et al (1979) Testicular function in patients with spinal cord damage. Horm Metab Res 11: 679-682.

25 Finsen V, Indredavik B, Fougner KJ (1992) Bone mineral and hormone status in paraplegics. Paraplegia 30: $343-347$.

26 Burnham R, Wheeler GD, Bhambhani Y, Belanger M, Eriksson P, Steadward RD (1994) Intentional induction of autonomic dysreflexia for performance enhancement in wheelchair athletes. Clin J Sport Med 4: $1-10$.

27 Mathias CJ, Christensen NJ, Corbett JL, Frankel HL, Spalding JMK (1976) Plasma catecholamines during paroxysmal neurogenic hypertension in quadriplegic man. Circ Res 39: 204-208.

28 Phelps G, Brown M, Chen J, Dunn M, Lloyd E, Stefaniuk ML (1983) Sexual experience and plasma testosterone levels in male veterans after spinal cord injury. Arch Phys Med Rehabil 64: 47-52.

29 Perronet F, Beliveau L, Boudreau G, Trudeau F, Brisson G, Nadeau R (1988) Regional catecholamine removal and release at rest and exercise in dogs. Am J Physiol 254: R663-R672.

30 Braddom RL, Rocco JF (1991) Autonomic dysreflexia: A survey of current treatment. Am J Phys Med Rehabil 70: 234-241.

31 Bhambhani YN, Eriksson P, Steadward RD (1991) Reliability of peak physiological responses during wheelchair ergometry in persons with spinal cord injury. Arch Phys Med Rehabil 75: 559-562.

32 Kreuz LE, Rose RM, Jennings JR (1972) Suppression of plasma testosterone levels and psychological stress. Arch Gen Psychiatry 26: 472-475.

33 Matsumoto K, Takeyasu K, Mizutani S, Hamanaka Y, Uozumi T (1970) Plasma testosterone levels following surgical stress in male patients. Acta Endocrinol 65: 11-17.

34 Lefkowitz KJ (1979) Direct binding studies of adrenergic receptors: biological, physiological and clinical implications. Ann Intern Med 91: 450-458.

35 Setchell BP, Waites GMH, Thorburn GD (1966) Blood flow in the testis of the conscious rat measured with Krypton. Circ Res 18: 755-765.

36 Eik-Ness KB (1964) On the relationship between testicular blood flow and secretion of testosterone in anesthetized dogs stimulated with human chorionic gonadotropin. Can J Physiol Pharmacol 42: 671-677.

37 Armstrong DT, Hansel W (1958) Effects of hormone treatment on testes development and pituitary function. Int J Fertil 3: 296-306. 